\title{
Kinetics of Influenza A/BANGKOK/1/1979(H3N2) Virus Thermal Inactivation in the Presence of Polyallylamine
}

\author{
N. A. Kontarov ${ }^{a, b}, *$ E. I. Dolgova ${ }^{b}$, I. V. Pogarskaya ${ }^{b}$, E. O. Kontarova ${ }^{c}$, and N. V. Yuminova ${ }^{b}$ \\ a Sechenov First Moscow State Medical University (Sechenov University), Ministry of Healthcare of the Russian Federation, \\ Moscow, 119991 Russia \\ ${ }^{b}$ Mechnikov Research Institute of Vaccines and Sera, Moscow, 115088 Russia \\ ${ }^{c}$ Federal Research and Clinical Center, Federal Medical and Biological Agency, Moscow, 115682 Russia \\ *e-mail: kontarov@mail.ru \\ Received September 18, 2020; revised January 21, 2021; accepted February 2, 2021
}

\begin{abstract}
Polyelectrolytes currently play an increasingly important role in antivirus therapy. Antiviral activity towards influenza virus, measles virus, herpes simplex virus type 1, and cytomegalovirus was demonstrated for the $6000 \mathrm{Da}$ polyelectrolyte polyallylamine. A nontoxic polyallylamine concentration of $30 \mu \mathrm{M}$ at which the compound retains its antiviral effect towards measles and influenza viruses but lacks any toxic effect on human cells was previously determined. It is well known, at the same time, that simultaneous virus exposure to physical environmental factors and chemical substances causes a more significant decrease in virus infectivity. Temperature is among these physical factors since thermal exposure causes virus inactivation. Analysis of virus thermal inactivation parameters is of high practical importance when it comes to the development of vaccines against influenza virus and to the study of how virus particles infectivity decreases on various surfaces. In this view, the study of kinetic and thermodynamical characteristics of influenza virus thermal inactivation in the presence of the antiviral preparation polyallylanime is of particular interest. The paper reports that thermal inactivation of influenza virus in the temperature range of $38-60^{\circ} \mathrm{C}$ in the presence of polyallylamine follows the first-order reaction kinetics. Thermodynamic parameters of influenza virus thermal inactivation evidence that influenza virus surface proteins are involved in the inactivation process as a result of their interaction with polyallylamine. The obtained results show that polyallylamine may be used to accelerate thermal inactivation of the influenza virus.
\end{abstract}

Keywords: polyelectrolyte, polyallylamine, influenza virus, thermal inactivation, hemagglutinating activity, viral infectivity

DOI: $10.3103 / \mathrm{S} 0096392521010028$

In order to reduce postvaccination complications, requirements imposed on inactivated influenza vaccines are becoming increasingly rigid. Various physical, chemical, and biological methods are used to inactivate the influenza virus [1-4]. The use of physical methods only is often insufficient to inactivate a virus vaccine strain, for which reason various chemical compounds that inactivate viral antigenic proteins, in particular hemagglutinin, at elevated temperatures are used as well. This reduces virus hemagglutinating activity (HA) and its infectivity. In the present work, polyelectrolyte (PE) polyallylamine (PAA) with the molecular weight of $6000 \mathrm{Da}$, which have been previously demonstrated to have an antiviral effect towards measles and influenza viruses at the concentration of $30 \mu \mathrm{M}$ [5], which is manifested by a decrease in their infectivity with no toxic effect on cells, was used as a chemical compound.

\section{MATERIALS AND METHODS}

Influenza virus. Influenza virus strain A/BANGKOK/1/1979(H3N2) was obtained from the collection of the Mechnikov Research Institute of Vaccines and Sera (Moscow, Russia) as a virus-containing suspension. The material was stored at $-80^{\circ} \mathrm{C}$.

Polyelectrolyte. A polyelectrolyte, polyallylamine hydrochloride with $M_{w}=6000 \mathrm{Da}$, in the final concentration of $30 \mu \mathrm{M}$ was used in this study (Sigma, United States). PAA solution in phosphate buffer had $\mathrm{pH}$ 7.4.

Cell culture. Canine cocker spaniel kidney epithelium cells MDCK II were grown in DMEM with the addition of penicillin $(100 \mathrm{U} / \mathrm{mL})$, streptomycin $(100 \mu \mathrm{g} / \mathrm{mL})$, and $10 \%$ fetal calf serum in the presence of $5 \% \mathrm{CO}_{2}$ at $37^{\circ} \mathrm{C}$. Cell viability was assessed in the MTT-assay [8]. This colorimetric assay is based on the ability of living cells to metabolize the tetrazolium stain MTT leading to a change in its color. Staining 
intensity was determined spectrophotometrically at $590 \mathrm{~nm} 24$ and $48 \mathrm{~h}$ after MTT addition.

Virus hemagglutinating activity. Virus HA activity was determined in a hemagglutination assay using $1.5 \%$ chicken erythrocyte suspension $[9,10]$. Initial $\mathrm{HA}$ activity of the studied strain was $32 \mathrm{HAU} / \mathrm{mL}$ (hemagglutination activity units $/ \mathrm{mL}$ ).

Virus infectivity. Virus infectious titre was determined based on the number of focus forming units (FFU) and expressed as FFU/mL [11]. Virus suspension was added to the MDCK II cell monolayer. Cell concentration in the well was $5 \times 10^{4}$ cells. The multiplicity of infection was 0.01 . Infection was carried out at room temperature in the dark for $1 \mathrm{~h}$, then virus suspension was removed. Cells were further grown in the DMEM-Avicel medium with the addition of $1.25 \%$ microcrystalline cellulose (Sigma, United States), $0.36 \%$ bovine serum albumin, and trypsin treated with chymotrypsin inhibitor L-1-tosylamide-2-phenylethylchloromethyl ketone (Sigma, United States) in the concentration of $1 \mu \mathrm{g} / \mathrm{mL}$ at $37^{\circ} \mathrm{C}$ in the presence of $5 \% \mathrm{CO}_{2}$. After $29 \mathrm{~h}$ of culturing, cultural liquid was discarded and cells were fixed with ice-cold $70 \%$ ethanol for $90 \mathrm{~min}$. Cells were then treated with the mouse antibodies against the influenza virus NP protein, and further with the secondary antimouse horseradish peroxidase-labelled antibodies (Sigma, United States). In order to detect horseradish peroxidase, two solutions were prepared, namely, the first solution containing $2.5 \mathrm{~mL}$ of dimethylformamide and $10 \mathrm{mg}$ of 3 -amino9-ethylcarbazole and the second solution containing $0.2 \mathrm{~mL} \mathrm{H}_{2} \mathrm{O}_{2}$ in $0.2 \mathrm{M}$ acetate buffer, $\mathrm{pH} \mathrm{5.0.} \mathrm{Two}$ solutions were mixed together and incubated at room temperature for $20 \mathrm{~min}$. The plate was further scanned and the number of FFU was calculated. The initial infectious virus titre was $5.4 \times 10^{6} \mathrm{FFU} / \mathrm{mL}$.

Virus thermal inactivation. Thermal inactivation of influenza virus was performed in the absence and with the addition of PAA to the virus-containing suspension to the final concentration of $30 \mu \mathrm{M}$. Incubation was carried out in the temperature range of $45-60^{\circ} \mathrm{C}$ to calculate a decrease in HA (HAU, \%) with respect to the initial HA, taken as $100 \%$, for $60 \mathrm{~min}$ and at $38-$ $60^{\circ} \mathrm{C}$ to calculate a decrease in the infectious titre (FFU, \%) with respect to the initial infectious titre, taken as $100 \%$, for $180 \mathrm{~min}$. All experiments with the influenza virus were performed in the Laboratory of Pediatric Viral Infections of the Department of Virology of the Mechnikov Research Institute of Vaccines and Sera. Statistical processing of the results obtained in the four replications of each experiment was performed using the parametric Student's $t$-test at 0.95 confidence probability in Excel 2010 (Microsoft Office). Approximation of kinetic curves was also performed in Excel 2010.

\section{RESULTS AND DISCUSSION}

Kinetic curves for influenza virus HA and infectious titre provided in Figs. 1a and $1 \mathrm{~b}$ show that virus thermal inactivation in the presence of $30 \mu \mathrm{M}$ PAA follows the first-order reaction kinetics:

$$
\begin{gathered}
R \stackrel{k_{\text {in }}}{\rightarrow} R_{\text {in }}, \\
\ln \left(\frac{\left[R_{t}\right]}{\left[R_{0}\right]}\right)=-k_{\text {in }} t,
\end{gathered}
$$

where $R$ and $R_{\text {in }}$ are active and inactivated virus forms, respectively, $\left[R_{t}\right]$ is virus HA and infectious titre at the time point $t$ in the course of virus thermal inactivation in the presence of $30 \mu \mathrm{M}$ PAA, $\left[R_{0}\right]$ is initial HA and infectious titre, and $k_{\text {in }}$ is thermal inactivation rate constant, $\mathrm{min}^{-1}$, which was calculated by fitting thermal inactivation kinetic dependencies to exponential functions with the exponential factor $-k_{\text {in }} t$. Thermal inactivation rate constants in the presence of $30 \mu \mathrm{M}$ PAA and without PE are given in Tables 1 and 2. The results provided in Tables 1 and 2 demonstrate that thermal inactivation rate constant in the presence of $30 \mu \mathrm{M}$ PAA is higher than the inactivation rate constant in the absence of PE. This observation may be accounted for by the inactivating effect of PAA, which binds with the surface proteins of the virion, thereby contributing to thermal inactivation, which resulted in the increase in HA and virus infectious titre drop rate. Thermodynamic parameters of virus thermal inactivation in the presence of and without PAA, the enthalpy $\Delta H^{\neq}$and entropy $\Delta S^{\neq}$of activation, were calculated using the kinetic parameters of influenza virus thermal inactivation and the Eyring equation (Fig. 2):

$$
k_{\text {in }}=\frac{k_{b} T}{h} e^{-\frac{\Delta H^{\ddagger}}{R T}} e^{\frac{\Delta S^{\ddagger}}{R}},
$$

where $T$ is temperature, $k_{b}$ is Boltzmann constant, $1.38 \times 10^{-23} \mathrm{~J} / \mathrm{K}$, and $h$ is Planck constant, $6.62 \times$ $10^{-34} \mathrm{~J} \mathrm{~s}$.

The enthalpy and entropy of activation for HA and virus infectivity in the absence of PAA were $\Delta H_{1}^{\neq}=$ $-124.5 \pm 8.1 \mathrm{~kJ} / \mathrm{mol}$ and $\Delta H_{2}^{\neq}=-141.27 \pm 4.6 \mathrm{~kJ} / \mathrm{mol}$ and $\Delta S_{1}^{\neq}=63.14 \pm 1.8 \mathrm{~kJ} /(\mathrm{K} \mathrm{mol})$ and $\Delta S_{2}^{\neq}=$ $104.75 \pm 5.4 \mathrm{~kJ} /(\mathrm{K} \mathrm{mol})$, respectively. The enthalpy and entropy of activation for HA and virus infectivity in the presence of $30 \mu \mathrm{M}$ PAA were as follows: $\Delta H_{1}^{\neq}=$ $-373.95 \pm 14.7 \mathrm{~kJ} / \mathrm{mol}$ and $\Delta H_{2}^{\neq}=-142.93 \pm$ $4.8 \mathrm{~kJ} / \mathrm{mol}$ and $\Delta S_{1}^{\neq}=871.4 \pm 21.2 \mathrm{~kJ} /(\mathrm{K} \mathrm{mol})$ and $\Delta S_{2}^{\neq}=160.44 \pm 5.8 \mathrm{~kJ} /(\mathrm{K} \mathrm{mol})$, respectively. The obtained thermodynamic parameters of virus thermal inactivation may be interpreted in the following way. Highly negative enthalpy of activation for HA and infectious titre points to inactivation of virion's surface proteins, with lower values for the enthalpy of activa- 
(a)

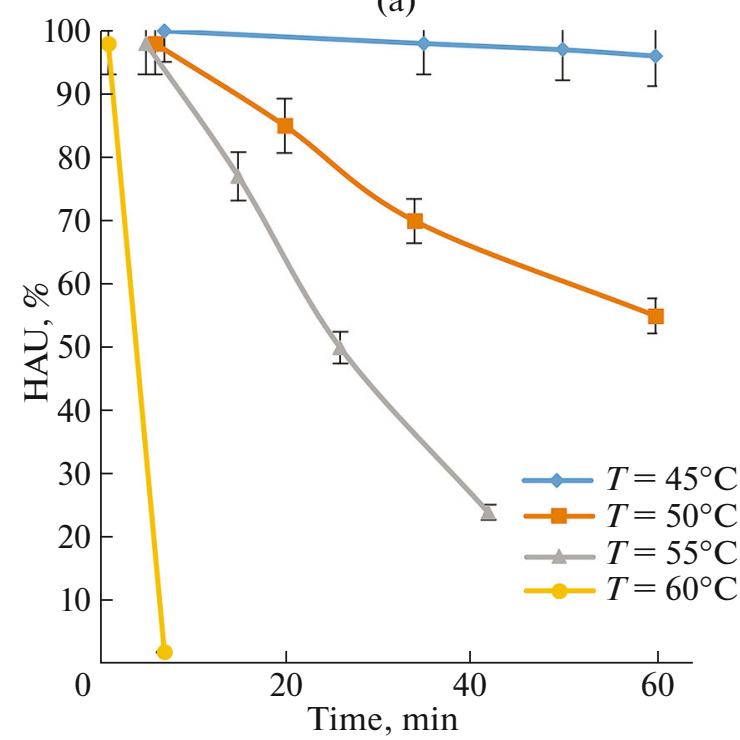

(b)

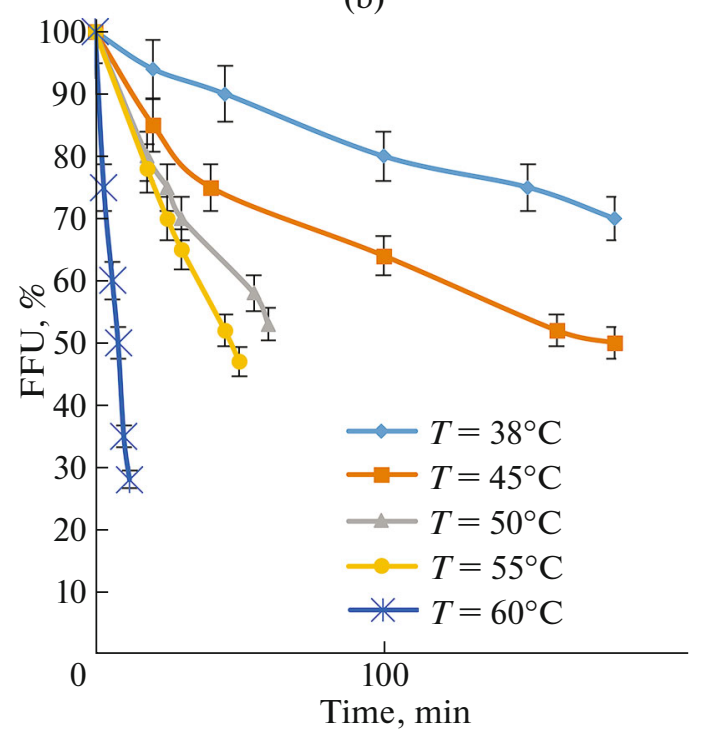

Fig. 1. Graphical assessment of thermal inactivation. (a) Changes in hemagglutinating activity of influenza virus A/BANG$\mathrm{KOK} / 1 / 1979(\mathrm{H} 3 \mathrm{~N} 2)$ in the presence of $30 \mu \mathrm{M}$ PAA, $\mathrm{pH}=7.4$. $X$ axis-time, min; $Y$ axis-HAU, \%. (b) Changes in the infectious activity of influenza virus A/BANGKOK/1/1979(H3N2) in the presence of $30 \mu \mathrm{M}$ PAA, $\mathrm{pH}=7.4$. $X$ axis-time, min; $Y$ axisFFU, \%.

tion for infectious titre being a result of solely protein structures but not virus ribonucleoprotein contributing to the decrease of virus infectious activity. Highly positive entropy of activation is observed when inactivation of virion's surface glycoproteins has a hydrophobic effect. The enthalpy of activation of virus thermal inactivation in the presence of $30 \mu \mathrm{M}$ PAA are significantly higher for HA and show no significant difference for infectious titre compared to thermal inactivation without PAA. This may be accounted for by the interaction between PAA and surface glycoproteins of the influenza virus virion, which additionally contribute to the energy of thermal inactivation.
Almost similar entropies of activation in the case of infectious titre may be explained by the fact that PAA interacts not only with the surface proteins but also with the virus ribonucleoprotein. High positive entropy of activation for HA in the case of virus thermal inactivation in the presence of PAA is associated with dehydration of surface proteins following their inactivation. Molar heat capacity increment $\Delta c_{p}$ may provide additional information on the PAA contribution into the thermodynamics of dehydration of surface glycoproteins in the course of virus thermal inactivation. Given the entropy of activation and using the formula (4), it is possible to calculate the molar heat

Table 1. Influenza virus thermal inactivation constants without PAA

\begin{tabular}{l|c|c|c|c|c}
\hline \multicolumn{1}{c|}{$k_{\text {in }}, \mathrm{min}^{-1}$} & $T=38^{\circ} \mathrm{C}$ & $T=45^{\circ} \mathrm{C}$ & $T=50^{\circ} \mathrm{C}$ & $T=55^{\circ} \mathrm{C}$ & $T=60^{\circ} \mathrm{C}$ \\
\hline Thermal inactivation of virus & - & $(2.78 \pm 0.05)$ & $(1.51 \pm 0.024)$ & $(3.43 \pm 0.062)$ & $(2.32 \pm 0.05)$ \\
hemagglutinating activity $(p<0.05)$ & $\times 10^{-4}$ & $\times 10^{-4}$ & $\times 10^{-4}$ \\
Thermal inactivation of virus infec- & $(2.87 \pm 0.048)$ & $(1.32 \pm 0.01)$ & $(3.29 \pm 0.061)$ & $(4.50 \pm 0.078)$ & $(1.30 \pm 0.02)$ \\
tivity $(p<0.05)$ & $\times 10^{-6}$ & $\times 10^{-5}$ & $\times 10^{-5}$ & $\times 10^{-5}$ & $\times 10^{-5}$ \\
\hline
\end{tabular}

Table 2. Influenza virus thermal inactivation constants in the presence of $30 \mu \mathrm{M}$ PAA

\begin{tabular}{l|c|c|c|c|c}
\hline \multicolumn{1}{c|}{$k_{\text {in }}, \min ^{-1}$} & $T=38^{\circ} \mathrm{C}$ & $T=45^{\circ} \mathrm{C}$ & $T=50^{\circ} \mathrm{C}$ & $T=55^{\circ} \mathrm{C}$ & $T=60^{\circ} \mathrm{C}$ \\
\hline Thermal inactivation of virus & - & $(8.0 \pm 0.09)$ & $(1.10 \pm 0.02)$ & $(4.0 \pm 0.06)$ & $(6.5 \pm 0.08)$ \\
hemagglutinating activity $(p<0.05)$ & & $\times 10^{-5}$ & $\times 10^{-3}$ & $\times 10^{-2}$ & $\times 10^{-2}$ \\
Thermal inactivation of virus & $(2.0 \pm 0.04)$ & $(4.01 \pm 0.07)$ & $(1.90 \pm 0.022)$ & $1.50 \times 10^{-2}$ & $(1.05 \pm 0.02)$ \\
infectivity $(p<0.05)$ & $\times 10^{-3}$ & $\times 10^{-3}$ & $\times 10^{-2}$ & $\times 10^{-1}$ \\
\hline
\end{tabular}




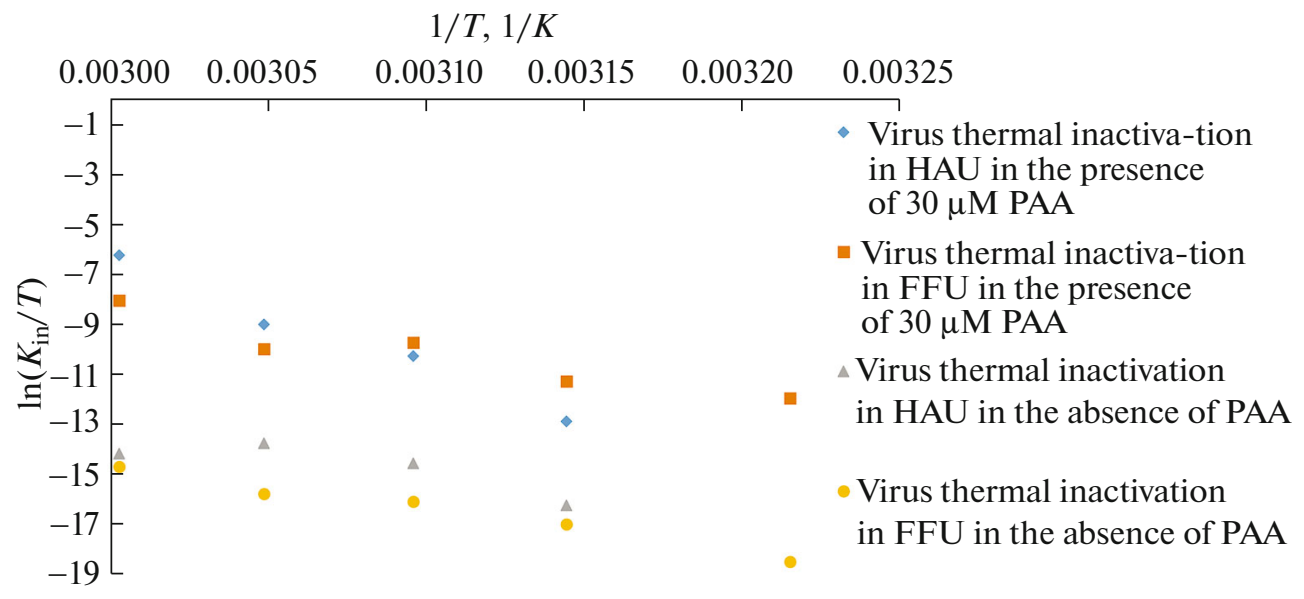

Fig. 2. Calculation of the enthalpy and entropy of influenza virus A/BANGKOK/1/1979(H3N2) thermal inactivation in the presence of $30 \mu \mathrm{M}$ PAA and without it, $\mathrm{pH}$ 7.4. $X$ axis $-1 / \mathrm{T}, 1 / \mathrm{K} ; Y$ axis $-\ln \left(k_{\mathrm{in}} / T\right)$.

capacity increment for HA and virus infectious titre in the course of virus thermal inactivation:

$$
\Delta S_{T}^{\neq}=\Delta S_{m}^{\neq}+\Delta c_{p} \ln \left(\frac{T}{T_{m}}\right),
$$

where $\Delta S_{T}^{\neq}$is change in the entropy of activation at $T$ and $\Delta S_{T}^{\neq}$is change in the entropy of activation at $T_{m}$, $T_{m}=334 \mathrm{~K}$.

Molar heat capacity increment $\Delta c_{p}$ values were calculated as the slope coefficients of the linear approximation equations based on the $\Delta S_{T}^{\neq}-\ln \left(\frac{T}{T_{m}}\right)$ dependency plots. The obtained negative $\Delta c_{p}$ values were as follows, $\Delta c_{p 1}=-1.14 \pm 0.08 \mathrm{~kJ} /(\mathrm{K} \mathrm{mol})$ and $\Delta c_{p 2}=$ $-0.44 \pm 0.06 \mathrm{~kJ} /(\mathrm{K} \mathrm{mol})$, for HA and influenza virus infectious titre thermal inactivation, respectively. Negative molar heat capacity increment for HA indicate that, in the presence of $30 \mu \mathrm{M}$ PAA, the "coiled molecule-molten dehydrated globule" transition takes place [7]. The obtained data correspond with the entropy of activation values obtained for virus HA thermal inactivation.

The struggle to control the pandemics of influenza virus and other enveloped respiratory viruses, including COVID-19, requires the development of new means for the prevention of acute respiratory viral infections, including chemical preparations that have an inactivating effect on all antigenic proteins of the virus. Special attention should be paid to the simultaneous use of physical and chemical factors of virus inactivation. Our results show that the use of PAA in combination with elevated temperature causes effective and fairly rapid inactivation of the influenza virus, with the PE used exerting an inactivation effect on all surface glycoproteins of the virion. The use of PAA, together with the temperature inactivation of the virus, may be utilized in the technology of inactivated, including whole-virion inactivated, anti-influenza vaccines.

\section{FUNDING}

The work was supported by the Russian Academic Excellence Project 5-1.

\section{COMPLIANCE WITH ETHICAL STANDARDS}

The authors declare that they have no conflicts of interest. No experimentation involving animals or humans was carried out by any of the authors.

\section{ADDITIONAL INFORMATION} 4867

Kontarov ORCID: https://orcid.org/0000-0003-00307569

Dolgova ORCID: https://orcid.org/0000-0001-8985-

Pogarskaya ORCID: https://orcid.org/0000-00033580-6277

Kontarova ORCID: https://orcid.org/0000-0002-55507875

Yuminova ORCID: https://orcid.org/0000-0002-77234038

\section{REFERENCES}

1. Bhatia, S., Lauster, D., Bardua, M., and Ludwig, K., Linear polysialoside outperforms dendritic analogs for inhibition of influenza virus infection in vitro and in vivo, Biomaterials, 2017, vol. 138, pp. 22-34.

2. Sundararajan, A., Ganapathy, R., Huan, L., and Dunlap, J., Influenza virus variation in susceptibility to inactivation by pomegranate polyphenols is determined by envelope glycoproteins, Antiviral Res., 2010, vol. 88, no. 1, pp. 1-9. 
3. Tuladar, E., Bouwknegt, M., Zwietering, M.H., Koopmans, M., and Duizer, E., Thermal stability of structurally different viruses with proven or potential relevance to food safety, J. Appl. Microbiol., 2012, vol. 112, no. 5, pp. 1050-1057.

4. Wang, W., Song, H.S., Keller, P.W., Alvarado-Facundo, E., Vassell, R., and Weissa, C.D., Conformational stability of the hemagglutinin of H5N1 influenza A viruses influences susceptibility to broadly neutralizing stem antibodies, J. Virol., 2018, vol. 92, no. 12.

5. Kontarov, N.A., Ermakova, A.A., Grebenkina, N.S., Yuminova, N.V., and Zverev, V.V., Investigation of the antiviral activity of polyelectrolytes against the influenza virus, Vopr. Virusol., 2015, vol. 60, no. 4, pp. 5-9.

6. Joly, M., A Physico-Chemical Approach to the Denaturation of Proteins, London: Academic Press, 1965.

7. Potekhin, S.A., Scanning microcalorimetry at high pressure: A new method for studying conformational and phase changes, Usp. Biol. Khim., 2018, vol. 58, pp. 285-312.
8. Mosmann, T., Rapid colorimetric assay for cellular growth and survival: Application to proliferation and cytotoxicity assays, J. Immunol. Methods, 1983, vol. 65, nos. $1-2$, pp. 55-63.

9. Wegmann, T.G. and Smithies, O., Improvement of the microtiter hemagglutination method, Transfusion, 1966, vol. 8, no. 1, pp. 67-73.

10. Pleshka, S., Stein, M., Schoop, R., and Hudson, J.B., Anti-viral properties and more of action of standardized echinacea purpurea extract against highly pathogenic avian influenza virus (H5N1, H7N7) and swine-origin H1N1 (S-OIV), Virol. J., 2009, vol. 6, artic. no. 197.

11. Payne, A.F., Binduga-Gajewska, I., Kauffman, E.B., and Kramer, L.D., Quantitation of flaviviruses by fluorescent focus assay, J. Virol. Methods, 2006, vol. 134, nos. $1-2$, pp. $183-189$.

Translated by E. Martynova 